\title{
Assessment of the learning curve: total laparoscopic hysterectomy versus total abdominal hysterectomy
}

\author{
Nutan Yadav*, Priyanka Tiwari, Abhishek Mangeshikar, Sushil Kumar
}

Department of Obstetrics and Gynecology, MGM Institute of Health Science, Navi Mumbai, Maharashtra, India

Received: 02 August 2019

Accepted: 09 September 2019

*Correspondence:

Dr. Nutan Yadav,

E-mail: nutanyadav1610@gmail.com

Copyright: () the author(s), publisher and licensee Medip Academy. This is an open-access article distributed under the terms of the Creative Commons Attribution Non-Commercial License, which permits unrestricted non-commercial use, distribution, and reproduction in any medium, provided the original work is properly cited.

\begin{abstract}
Background: Abdominal hysterectomy is the most frequented way of hysterectomy in the world; today we have a lot of techniques for hysterectomy. Total Laparoscopic Hysterectomy (TLH) versus Total Abdominal Hysterectomy (TAH) needs experience an assessment of the learning curve. Objective of the study was to determine the feasibility and safety of TLH and TAH.

Methods: Total 100 women were taken for study. Operating time, estimated blood loss, operating complication and length of stay in hospital were noted for each patient. The success rates of TLH were more compared to TAH. The operating time estimated blood loss, conversion to laparotomy was directly proportional to size of uterus.

Results: There were no statistically significant differences between the two groups regarding age, body mass index (BMI), specimen weight, pre-operative hemoglobin $(\mathrm{Hb})$ value and rates of the complications. The mean postoperative $\mathrm{Hb}$ value was significantly higher in group TLH than group TAH $(11.3 \pm 0.7 \mathrm{gr} / \mathrm{dl}$ versus $10.6 \pm 1.6, \mathrm{p}=$ $0.03)$. The mean time of operation was significantly longer in TLH than group TAH $(105.4 \pm 22.9$ minutes versus $74 \pm 18, \mathrm{p}<0.001)$. The mean duration of hospital stay was statistically shorter in TLH compared to the TAH $(2.47 \pm 0.5$ days versus $4.86 \pm 1.1, \mathrm{p}<0.001)$.

Conclusions: Advantage of TLH over TAH are less blood loss, fewer wound infection and fever, smaller incisions, with less pain, shorter hospitalization time, speedier recovery.
\end{abstract}

Keywords: Total abdominal hysterectomy, Total laparoscopic hysterectomy

\section{INTRODUCTION}

Hysterectomy is the most common major surgical procedure performed on women all over the world next to caesarean section. ${ }^{1}$ Today authors have a lot of techniques for hysterectomy. Uterus may be removed abdominal, vaginal or laparoscopic. In India, the incidence of hysterectomy is about 4-6\% of adult Indian women out of which $90 \%$ are performed for benign indications. $^{2}$ India approximately 2,310,263 women undergo hysterectomy every year. ${ }^{3}$ Women with pelvic pain, large fibroid uteri, multiple prior surgeries, or need for concomitant prolapse such as sacrocolpopexy. The most frequently performed major surgical procedure for women of the perimenopausal and menopausal. In the early days, hysterectomy, or the hysterectomy was done either by the vaginal or the abdominal route. Women with uterus larger than 18 weeks are not considered for laparoscopy, but with advanced technique, even larger uteri can be removed provided there is adequate space in the abdomen and pelvis for port placement and dissection. Pelvis is examined for etiology of pain such as endometriosis, methodological management of adhesions. It is contraindicated in women who are medically 
unstable for surgery. Vaginal route was more preferred as it involved less pain and less contraindications, lower morbidity and quicker recovery. ${ }^{4}$ Women who have tubal or ovarian malignancy considered for Total Abdominal Hysterectomy (TAH) approach. Most of these women hail from rural sides belong to the working class and are financially challenged. Keeping this demographic profile of Indian population in mind, it is important that the procedure of hysterectomy for Indian population should be cost-effective and with minimum duration of hospital stay. There is needs a learning experience to determine the feasibility and safety of total TLH and TAH. Therefore, aim of this study is to evaluate and compare the results of total laparoscopic hysterectomy (TLH) and total abdominal hysterectomy (TAH) cases which were feasible and safe.

\section{METHODS}

This is a retrospective observational study carried out at MGM Kamothe, Navi Mumbai. All the TLH and TAH cases performed during the period from January 2018 to January 2019. 100 patients were taken for the observational study. 50 patients underwent TLH and other 50 patients underwent TAH. The bed head records of all the patients were retrieved and analyzed with using statistical method. All the patients were conducted by taking proper consent after explaining the advantages and disadvantages of laparoscopic procedure. Data regarding the age, parity, indication of surgery, size of the uterus, history of previous surgery, concomitant surgery performed were noted. All patients were given dulcolax 2 tab HS on the day before surgery for bowel preparation. Most of the surgeries were performed under GA. Preoperative ceftriaxone was given to all cases as antibiotic prophylaxis. Surgeries were done by using bipolar forceps, monopolar. Abdominal entry was mostly by 10 $\mathrm{mm}$ trocar except a few cases where verses needle was used.

Uterine manipulator was used in almost all the cases. Only in a small number of cases myoma screw was used for uterine elevation. In case of big uterus laparoscopic morcellator was used, in rest of cases specimen was retrieved through vagina. Vaulting closure was done by endosuturing in majority of cases. All the intra operative complications like injury to bowel and urinary tract were retrieved from the operation theatre note. Conversion to laparotomy and post-operative morbidities like fever, UTI, port infection, respiratory infection, vault bleeding was also noted. Duration of hospital stay is Generally 48 hours in cases of TLH.

\section{Inclusion criteria}

- Eligible patients for the study in case there was no suspicion of endometrial carcinoma beyond FIGO stage 1 and the size of the uterus did not exceed 18 weeks of gestation. Chest X-ray was performed in all patients, but no routine hysteroscopy was performed for preoperative staging.

\section{Exclusion criteria}

- Patients with known previous lower abdominal midline incision were excluded from the study.

\section{Statistical methods}

Data were entry in excel sheet and statistically analyzed. The mean difference between continuous variables was estimated using student t-test and chi-square test and pvalue of less than 0.05 was considered statistically significant.

\section{Steps towards Successful TLH}

\section{Preparation and positioning}

Patients are placed in a dorsal lithotomy position. The armsare placedat the sides and a foam mattress is situated directly under the patient to prevent sliding during steep Trendelenburg. Table is kept in low position and monitor directly facing each surgeon. The surgeon should be familiar with all the equipments in the operating room and should routinely inspect equipment for any malfunction. In general, it is important for the surgeon to simplify the equipment list as much as possible. This prevents crowding in the operating room and facilitates room turnover and staff familiarity with the equipment being used.

\section{Insertion of uterine manipulator}

Generally, use the RUMI® Uterine Manipulator (CooperSurgical, Trumbull, CT) is preferred; however, in patients with a very narrow introitus Vcare is used. Placing RUMI can be challenging, there are several tricks that can simplify this task. The tip can be difficult to attach to the shaft, but dipping the distal end of the shaft in lubricant prior to attaching the tip greatly facilitates this step. The pneumo-occluder then slides over the tip and onto the shaft followed by attachment of the appropriately sized $\mathrm{KOH}$ ring $(3,3.5$, and $4 \mathrm{~cm}$ in width).

It is important to choose the correct size because a small ring will not delineate the vaginal fornices and a large ring may increase the risk of a ureteral injury. Next, place a 0-monofilament suture through the anterior lip of the cervix, thread this through the $\mathrm{KOH}$ ring, and secure with a hemostat. Insert the tip of the RUMI as far into the cervix as it will go, then release the tenaculum while keeping tension on the cervical stitch. This prevents the uterus from moving cephalad as the tenaculum is removed. After confirming correct placement by palpation or direct visualization, tie the suture to the handle to facilitate specimen removal through the vagina at the end of the case. A Foley catheter is inserted into the 
bladder and finally the pneumo-occluder is filled with 60 to $100 \mathrm{cc}$ of saline.

\section{Abdominal entry and trocar placement}

A $5 \mathrm{~mm}$ skin incision is made at the deepest part of the umbilicus. Deepest part of the umbilicus is elevated with a Kocher clamp and a verse needle was inserted into the peritoneal cavity. The gas tubing is already connected to the needle to reduce manipulation following insertion. An easy way to confirm intraperitoneal entry is to look for a negative pressure reading on the insufflator. Once intraperitoneal pressure has reached $15 \mathrm{mmHg}$, an optical trocar through the umbilicus was inserted under direct vision, followed by a complete survey of the abdomen to rule out any visceral injury at the time of entry. The lower quadrant trocar sleeves are placed under direct vision. These trocars are placed lateral to the rectus abdominis muscles, $2 \mathrm{~cm}$ above and $2 \mathrm{~cm}$ medial to the anterior superior iliac spine. Usually, a $5 \mathrm{~mm}$ trocar is placed on the right and a $12 \mathrm{~mm}$ trocar on the left. In addition, a $5 \mathrm{~mm}$ trocar is placed approximately $8 \mathrm{~cm}$ above and parallel to the lower left trocar site. This port will, in most cases, end up being nearly parallel to the umbilical trocar. The $12 \mathrm{~mm}$ port site is ideal for needle passage and specimen retrieval.

\section{Hug the ovaries}

The Infundibulo Pelvic (IP) ligament or the utero-ovarian ligament is initially desiccated with a bipolar grasper. The IP ligament or utero-ovarian ligament is then transected close to the ovary using the Harmonic ${ }^{\circledR}$ Scalpel. During this step of the procedure, the uterine manipulator is being pushed upwards and to the contra lateral side to provide maximal visualization.

\section{Mobilize the bladder}

Transect the round ligament and separate the anterior and posterior leaves of the broad ligament with the Harmonic scalpel. Next, identify the vesicouterine peritoneal fold and continue the dissection anteriorly, thereby mobilizing the bladder off the lower uterine segment.

\section{Secure the uterine vessels}

Skelenetize the uterine vessels with harmonic scalpel first then desiccate the ascending uterine vessels with the bipolar grasper at the level of internal cervical OS. Complete desiccation of the vessels can be assessed visually by observing the bubbles coming and going during this process; when the bubbles stop forming the vessel is desiccated and safe to transect with the harmonic scalpel. 2 cuts were made with the harmonic scalpel in an inverted V-shape anterior and medial and posterior and medial to the vascular pedicle. This enables the vascular pedicle to fall out laterally, thereby providing easy and a vascular access to the cervical cup. This averts ureteral injury and provides a healthy vascular pedicle that can be safely desiccated further in the event of bleeding.

\section{Separate the uterus and cervix from vaginal apex}

Identify the vaginal fornices while pushing cephalad with the uterine manipulator. Indentation of the $\mathrm{KOH}$ colpotomizer is seen or palpates it with a laparoscopic instrument. The Harmonic scalpel is then used to cut circumferentially around the cut.

\section{Removal of uterus}

Pull the uterus into the vagina if it fits. The uterus can remain there to maintain pneumoperitoneum during suturing. Alternatively, the uterus is removed and a glove with a pair of $4 \times 4$ sponges is placed into the vagina to maintain pneumoperitoneum. If the uterus is too large to fit through the vagina, it can be carefully morcellated transvaginally by using a 10-blade scalpel and triple hooks for retraction.

\section{Vaginal cuff closure}

Closure begins at the distal angle of the vaginal cuff and proceeds in a running fashion, making sure to include the vaginal mucosa and the pubocervical and rectovaginal fascia. Each bite should be approximately $1 \mathrm{~cm}$ in thickness. A lapratomy is then placed at the end of suture and the needle is cut free and removed through the $12 \mathrm{~mm}$ port. The pelvis can now be irrigated and hemostasis at all sites is assured.

\section{Port site closure}

The fascia at the $12 \mathrm{~mm}$ incision in the left lower quadrant is closed using 0 vicryl sutures with a fascia closure device. The skin is closed with 4-0 monocryl suture in a continuous subcutaneous fashion. The $5 \mathrm{~mm}$ incisions are closed with Dermabond.

\section{Steps of total abdominal hysterectomy}

Open the abdomen and visualize/palpate the pelvis, abdomen and retroperitoneal area to evaluate the presence of normal or abnormal findings and anatomy. Place a retractor if needed to provide for adequate exposure for safe pelvic surgery. Grasp the round ligament, uteroovarian ligament and fallopian tube. Clamp on each side will manipulate the uterus. Elevating the uterus out of the pelvis, the anatomy is reevaluated and any adhesions to adjacent bowel or omentum are freed. The round lighament on each side is ligated and divided, opening the retroperitoneal space. If the ovaries are to be preserved, the utero ovarian pedicle is clamped, divided and ligated. If the ovary is to be removed, the retroperitoneal space is opened, the ureter is identified and infundibulo pelvic ligament is isolated, clamped, divided and ligated. Then it was repeated on the opposite side. The bladder is then dissected free from the anterior wall of the lower uterine 
segment and the cervix so that the anterior vaginal wall is exposed. The uterine vessels are skeletenized on both sides at the level of the lower uterine segment. The uterine vessels are clamped bilaterally, the uterine vessels are then divided and suture ligated. The exposure of anterior and posterior vaginal wall is checked below the cervix. The remaining portion of broad ligament on each side of cervix is clamped, divided and ligated using a series of clamps until the cervix is reached, and the broad ligament on each side has been detached from the lateral cervix and upper vagina is well exposed with the uterus strongly elevated out of the pelvis, large right angle clamps are placed across the vagina just below the cervix-one from each side with tips meeting the middle. The vagina is divided with a knife or a long heavy curved scissors above the clamps, and the uterus and cervix are passed off the operative field. The vaginal apex is closed. Heaney suture ligatures can be used on each side incorporating the uterosacral and cardinal ligaments in to the cuff for support. The pelvis is irrigated with warm, sterile saline and hemostasis is checked. The packs and retractors are removed and the sigmoid colon is carefully replaced in the pelvis the abdominal wall is closed.

\section{Contraindications of TLH}

Medical conditions that would limit pneumoperitoneum adequate ventilation were maintained. Severe abdominal or pelvic adhesive disease (advanced pregnancy, bulky uterine size). Malignancy or tumor in which a large specimen needs to be removed intact (ovarian cancer, dermoid leiomyoma with necrotic degeneration. In all cases decision for hysterectomy is dependent on skills of surgeon. Insufficient knowledge skill, experience of surgeon remain the most common reasons for converting any laparoscopic hysterectomy to abdominal route hysterectomy.

\section{RESULTS}

A total 100 hysterectomies were performed during the study period from January 2018 to January 2019. 50 patients underwent TLH and other 50 patients underwent TAH. Comparison was made between TLH and TAH. Age group taken in this study is $40-65$ years.

Parity 2 - 2.5, Table 1 showed indications for TAH and TLH. The most common indication for both is fibroid uterus Table 2 showed maximum patients had uterine size 8-10 weeks size who underwent TAH and the least were 12-16 weeks. Major blood loss was seen in 2 patients. The 1 patient had minor ureteric injury and 1 patient had bladder injury. Bowel injury was seen in 1 patient.

The 1 patient had fibroid uterus injury, fever seen in 1 patient and 2 patients had pelvic pain and no wound infection in TLH. Laparotomy conversion was done for 1 multiple fibroid uterus. Total numbers of patients with complications were 9 in TLH. And blood loss was seen was seen in 3 patients. 2 patients had minor ureteric injury and 1 patient had bladder injury. Bowel injury was seen in 2 patients. And wound infection in 1 patient fever seen in 2 patients and 2 patients had pelvic pain. Abdominal conversion was done for 1 multiple fibroid uterus.

Total numbers of patients with complications were 18 in TLH. The common complaints were blood loss TLH in $2(4 \%)$ patients and in TAH $3(6 \%)$ patients, $1(1 \%)$ patients who had TLH and $2(2 \%)$ patients who had TAH ureteric injury. Bladder injury $(1 \%)$ and fibroid uterus (1\%) Wound infection in TAH (2\%) and (2\%) and (6\%) pelvic pain, (1\%) and (2\%) Fever (Table 2).

Table 1: Patients' characteristics: TLH verses TAH.

\begin{tabular}{|c|c|c|c|}
\hline \multirow{2}{*}{$\begin{array}{l}\text { Patients" } \\
\text { characteristics }\end{array}$} & TLH & TAH & \multirow{2}{*}{$\begin{array}{l}P \text { - } \\
\text { value }\end{array}$} \\
\hline & $(n=50)$ & $(n=50)$ & \\
\hline Age (years) & $41.3 \pm 3.0$ & $46.1 \pm 4.0$ & 0.216 \\
\hline Parity & $2(0-4)$ & $2(0-6)$ & 1 \\
\hline BMI $\left(\mathrm{kg} / \mathrm{m}^{2}\right)$ & $24.1 \pm 2.0$ & $25.5 \pm 3.1$ & 0.219 \\
\hline Premenopausal & $5(10 \%)$ & $3(6 \%)$ & 0.46 \\
\hline Postmenopausal & $45(90 \%)$ & $47(94 \%)$ & 0.46 \\
\hline $\begin{array}{l}\text { Data are given } \\
\text { (percentages); TLH: } \\
\text { Total Abdominal Hy } \\
\text { Hemoglobin }\end{array}$ & $1 \pm$ standar & viation & \\
\hline
\end{tabular}

Table 2: Clinical results of patients: TLH verses TAH.

\begin{tabular}{|c|c|c|c|}
\hline \multirow{2}{*}{ Variables } & TLH & ТАH & \multirow{2}{*}{$\begin{array}{l}P \text { - } \\
\text { value }\end{array}$} \\
\hline & $(n=50)$ & $(n=50)$ & \\
\hline Uterine size $(\mathrm{cm})$ & $11.16 \pm 2.9$ & - & - \\
\hline $\begin{array}{l}\text { Hospital stay } \\
\text { (days) }\end{array}$ & $2.47 \pm 0.5$ & $4.86 \pm 1.1$ & $<0.001$ \\
\hline $\begin{array}{l}\text { Pre-operative } \mathrm{Hb} \\
\text { value }(\mathrm{g} / \mathrm{dl})\end{array}$ & $12.6 \pm 1.5$ & $12.3 \pm 0.8$ & 0.349 \\
\hline $\begin{array}{l}\text { Post-operative } \mathrm{Hb} \\
\text { value }(\mathrm{g} / \mathrm{dl})\end{array}$ & $11.3 \pm 0.7$ & $10.6 \pm 1.6$ & 0.03 \\
\hline $\begin{array}{l}\text { Duration of } \\
\text { surgery (minutes) }\end{array}$ & $105.4 \pm 22.9$ & $74.5 \pm 18.1$ & $<0.001$ \\
\hline Blood losses & $2(4 \%)$ & $3(6 \%)$ & 0.646 \\
\hline Ureteric injury & $1(2 \%)$ & $2(4 \%)$ & 0.557 \\
\hline Bladder injury & $1(2 \%)$ & $1(2 \%)$ & 1 \\
\hline Bowel injury & $1(2 \%)$ & $2(4 \%)$ & 0.557 \\
\hline Fibroid uterus & $1(2 \%)$ & $1(2 \%)$ & 1 \\
\hline Wound infection & $0(0 \%)$ & $1(2 \%)$ & - \\
\hline Fever & $1(2 \%)$ & $2(4 \%)$ & 0.557 \\
\hline Pelvic pain & $2(4 \%)$ & $6(12 \%)$ & 0.14 \\
\hline
\end{tabular}

\section{DISCUSSION}

In a lot of studies which compare laparoscopic hysterectomy and abdominal, because of lower complication incidence. Hysterectomy is the most common major surgical procedure for gynecological conditions. There was no statistically significant 
difference between two groups with mean age, BMI and the indication of hysterectomy (Table 1).

Majority of the patients were above the 40 years age group with most of them having attained menopause earlier. There were only $5(10 \%) / 3(6 \%)$ women who were in the premenopausal age group. $45(90 \%) / 47$ $(94 \%)$ of these women had a previous surgery (Table 1 ). The age group who underwent laparoscopic surgery was slightly lesser than those patients who underwent either abdominal. ${ }^{5}$ Table 2 shows maximum patients had uterine size 8-10 weeks size who underwent TAH and the least were 12-16 weeks and uterine size $\mathrm{cm}(11.16 \pm 2.9)$. Weight of surgical specimen, preoperative hemoglobin $(\mathrm{Hb})$ value and complication rates was similar for both two groups and there was no statistically significant difference. Mean postoperative $\mathrm{Hb}$ value was higher in group 1 than group 2 and this was statistically significant $(11.3 \pm 0.7 \mathrm{gr} / \mathrm{dl}-10.6 \pm 1.6, \mathrm{p}=0.02)$. Mean operation time was longer in group 1 than group 2 and this was statistically significant $(105.4 \pm 22.9$ minutes-74.5 \pm 18.1 , $\mathrm{p}<0.001)$. Mean hospitalization time was shorter for patients who undergone TLH than patients who undergone TAH and this was statistically significant (2.1 \pm 2.1 day-4.86 $\pm 1.1, \quad \mathrm{p}<0.001)$. Other common complaints were blood loss TLH in $2(4 \%)$ patients and in TAH $3(6 \%)$ patients, $1(1 \%)$ patients who had TLH and $2(2 \%)$ patients who had TAH ureteric injury. Bladder injury $(1 \%)$ and fibroid uterus $(1 \%)$ Wound infection in TAH $(2 \%)$ and $(2 \%)$ and (6\%) pelvic pain, (1\%) and $(2 \%)$ fever (Table 2$)$. In a lot of studies intraoperative and preoperative blood loss in laparoscopic hysterectomy was less than abdominal hysterectomy. ${ }^{6-9}$ In the study postoperative hemoglobin value was higher in TLH patients than TAH patients and this was statistically significant. Because of laparoscopic surgery needs experience, while laparoscopic hysterectomy cases take a long time at the beginning, with progressive experience operation time is getting shorter. Anyway, studies report that laparoscopic hysterectomy takes longer operation time than abdominal hysterectomy. ${ }^{6,7,10}$ TLH had a longer operation time and better quality of life, yet, less blood loss, shorter hospital stays, less postoperative pain and fever complications. The duration of the surgery also was prolonged compared the other types, but the duration of the hospital stay was far less and the post-operative pain also was comparatively lesser. ${ }^{11-15}$ Although the cost of the procedure was higher, it was preferred by many patients due to the less pain and faster recovery. ${ }^{5,16-18}$

\section{CONCLUSION}

TLH is preferred over TAH. The advantage of TLH over TLH are less blood loss, fewer wound infection and fever, smaller incisions, with less pain, shorter hospitalization time, speedier recovery. TLH is associated with longer operating time and better quality of life. Laparoscopic hysterectomy is a safe and suitable procedure for chosen patients. It affords patients advantages like less peri-operative morbidity, and faster return to activity. TLH is favored in those patients who are morbidly obese.

Funding: No funding sources

Conflict of interest: None declared

Ethical approval: The study was approved by the Institutional Ethics Committee

\section{REFERENCES}

1. Wu JM, Wechter ME, Geller EJ, Nguyen TV, Visco AG. Hysterectomy rates in the United States, 2003. Obstet Gynecol. 2007;110(5):1091-5.

2. Singh AJ, Arora AK. Effect of uterine prolapse on the lines of rural North Indian women. Singapore. J Obstet Gynecol. 2003;34:52-8.

3. Drahonovsky J, Haakova L, Otcenasek M, Krofta L, Kucera E, Feyereisl J. A prospective randomized comparison of vaginal hysterectomy laparoscopically assisted vaginal hysterectomy, and total laparoscopic hysterectomy in women with benign uterine disease. Eur J Obstet Gynecol Reprod Biol. 2010;148(2):172-6.

4. Clinch J. Length of hospital stay after vaginal hysterectomy. $\mathrm{Br} \quad \mathrm{J}$ Obstet Gynaecol. 1994;101(3):253-4.

5. Mccracken G, Hunter D, Morgan D, Price JH. Comparison of laparoscopic-assisted vaginal hysterectomy, total abdominal hysterectomy and vaginal hysterectomy. Ulster Med J. 2006;75(1):54-8.

6. Olsson $\mathrm{JH}$, Ellstro “ $\mathrm{m} \mathrm{M}$, Hahlin M. A randomized prospective trial comparing laparoscopic and abdominal hysterectomy. $\mathrm{Br} \mathrm{J}$ Obstet Gynaecol. 1996;103(4):345-50.

7. Howard FM, Sanchez R. A comparison of laparoscopic assisted vaginal hysterectomy and abdominal hysterectomy. J Gynecol Surg. 1993;9(2):83-90.

8. Nezhat F, Nezhat C, Gordons S, Wilkins F. Laparoscopic versus abdominal hysterectomy. J Reprod Med. 1992;37(3):247-50.

9. Perino A, Cucinella G, Venezia R, Castelli A, Cittadini E. Total laparoscopic hysterectomy versus total abdominal hysterectomy: an assessment of the learning curve in a prospective randomized study. Hum Reprod. 1999;14(12):2996-9.

10. Çelik C, Abali R, Tasdemir N, Aksu E, Çalışkan H, Akkuş D. Total Laparoskopik Histerektomi ve Abdominal Histerektomi Karşılaştırılması; Klinik Sonuçlar. JCAM. 2014;5(6):490-3.

11. Nieboer TE, Johnson N, Lethaby A, Tavender E, Curr E, Garry R, et al. Surgical approach to hysterectomy for benign gynaecological disease. Cochrane Database Syst Rev. 2009;8(3):CD003677.

12. Donnez O, Jadoul P, Squifflet J, Donnez J. A series of 3190 laparoscopic hysterectomies for benign disease from 1990 to 2006: evaluation of complications compared with vaginal and abdominal procedures. Int J Obst Gyn. 2009;116(4):492-500.

13. Wattiez A, Soriano D, Cohen SB, Nervo P, Canis M, Botchorishvili $\mathrm{R}$, et al. The learning curve of total 
laparoscopic hysterectomy: comparative analysis of 1647 cases. J Am Assoc Gynecol Laparosc. 2002;9(3):339-45.

14. Cho HY, Choi KJ, Lee YL, Chang KH, Kim HB, Park SH. Comparison of two bipolar systems in laparoscopic hysterectomy. J Society Laparoendo Surg. 2012;16(3):456-60.

15. Kluivers KB, Hendriks JC, Mol BW, Bongers MY, Bremer GL, Vet HC, et al. Quality of life and surgical outcome after total laparoscopic hysterectomy versus total abdominal hysterectomy for benign disease: a randomized, controlled trial. J Minim Invasive Gynecol. 2007;14(2):145-52.

16. Donnez O, Donnez J. A series of 400 laparoscopic hysterectomies for benign disease: a single centre, single surgeon prospective study of complications confirming previous retrospective study. Int $\mathrm{J}$ Obst
Gyn. 2010;117(6):752-5.

17. Karaman Y, Bingol B, Gunenç Z. Prevention of complications in laparoscopic hysterectomy: experience with 1120 cases performed by a single surgeon. J Minim Invasive Gynecol. 2007;14(1):78-84.

18. Bojahr B, Raatz D, Schonleber G, Abri C, Ohlinger R. Perioperative complication rate in 1706 patients after a standardized laparoscopic supracervical hysterectomy technique. J Minim Invasive Gynecol. 2006;13(3):183-9.

Cite this article as: Yadav N, Tiwari P, Mangeshikar A, Kumar S. Assessment of the learning curve: total laparoscopic hysterectomy versus total abdominal hysterectomy. Int J Reprod Contracept Obstet Gynecol 2019;8:4045-50. 